\title{
(t)
}

\section{O CENÁRIO DA POLÍTICA URBANA BRASILEIRA E O SERVIÇO SOCIAL: CONTRIBUIÇÕES PARA O DEBATE}

\author{
The Brazilian urban politic stage and the Social Work: \\ contributions to debate
}

\section{Mauricléia Soares dos Santos ${ }^{1}$ Núria Pardillos Vieira² Tânia Maria Ramos de Godoi Diniz ${ }^{3}$}

\section{RESUMO}

Em uma sociedade profundamente desigual como a brasileira, a luta pelo direito à cidade tem sido impulsionada pelos movimentos sociais e setores da sociedade civil compromissados com a perspectiva da construção de uma nova ordem societária, sob parâmetros democráticos. Todavia, o que se observa, na dinâmica urbana atual, é a sociabilidade do capital alimentando desigualdades socioeconômicas, adensamento das periferias urbanas e despovoamento das áreas centrais das cidades, reforçados pelo assalariamento precário, pela informalidade predominante nas relações de trabalho e pela autoconstrução das moradias, poderosos instrumentos de amortecimento dos conflitos sociais, aspectos que, dificilmente, preenchem os requisitos da democracia. Assim, tendo em vista a crítica às determinações da sociabilidade do capital, este texto pretende apontar características e aspectos da política urbana no Brasil, discutindo as determinações e mediações que possibilitam contemplar a diver-

\footnotetext{
${ }^{1}$ Assistente Social, Mestre pela PUC-SP e professora das Faculdades Metropolitanas Unidas (SP) e das Faculdades Mauá (SP). E-mail: <mauri.lilas@gmail.com>. ${ }^{2}$ Assistente Social, Doutoranda da PUC-SP. E-mail: <nuriapardillos@gmail.com>. ${ }^{3}$ Assistente Social, professora adjunta do curso de Serviço Social da Universidade Federal de São Paulo (UNIFESP). E-mail: <tgdiniz@uol.com.br>.
} 
sidade social e econômica da população brasileira na luta contra a mercantilização da terra e na defesa do direito à cidade.

\section{PALAVRAS-CHAVE}

Política, Urbanização, Serviço Social, Capitalismo.

\section{ABSTRACT}

The right to the city is a framework for debate on rights and responsibilities, taking forward the social movements and representative associations of different segments of the community, in order to fight social inequalities and exclusion and to have a democratic management of the cities. Within the global context, the capital accumulation and the urbanization process express the inequality economic and social conditions of the population, and reproduce great contradictions and conflicts of the contemporary society. Through the present paper, we intend to discuss the urban politic, his historical and cultural process of implementation and his legislation, policies and programs, in order to mobilize public interest and debate on the right to the city, aiming to advance the national policy of urban development. And yet, by understanding these processes, we can discuss these contradictions. We deeply critic the land mercantilization as a form of capital accumulation and vigorously defend the right of the city.

\section{KEYWORDS}

Politics. Urbanization. Social Work. Capitalism.

Submetido: $17 / 6 / 2012$

Aceito: $19 / 9 / 2012$

\section{INTRODUÇÃO}

Em uma sociedade profundamente desigual como a brasileira, a luta pelo direito à cidade tem sido impulsionada pelos movimentos sociais e setores da sociedade civil compromissados com a perspectiva da construção de uma nova ordem societária, sob parâmetros democráticos.

As lutas sociais por cidades justas são traduzidas na defesa de políticas e programas que garantam o acesso de todos os trabalhadores aos direitos humanos fundamentais, entre os quais a moradia digna, que pressupõe água e saneamento, transporte público acessível e eficiente, e assentam-se nos princípios da função social da propriedade e da cidade. 
Todavia, o que se observa na dinâmica urbana atual é a sociabilidade do capital alimentando desigualdades socioeconômicas, o adensamento das periferias urbanas e despovoamento das áreas centrais das cidades, reforçados pelo assalariamento precário, pela informalidade predominante nas relações de trabalho e pela autoconstrução das moradias, todos poderosos instrumentos de amortecimento dos conflitos sociais que, dificilmente, preenchem os requisitos da democracia.

Nas quatro últimas décadas, vive-se o que tem sido denominado de ofensiva do capital a partir da crise da década de 1970, cujo objetivo é a recuperação e manutenção das taxas de lucro, o que ocorreu em três direções: reestruturação produtiva, mundialização do capital e a contrarreforma neoliberal que atingiu os Estados nacionais (BEHRING, 2009, p. 70). Acrescenta-se a esses elementos a desterritorialização dos processos de produção e mudanças nas dinâmicas das cidades, a precarização e desregulamentação do trabalho e o processo de financeirização do capital, com o fortalecimento do capital rentista. A par dessa dinâmica, observam-se processos de urbanização acelerada, de polarização e tensionamento das relações campo-cidade, de concentração do crescimento econômico sob a lógica mercantilista do capital, intensificando a estrutura desigual das classes sociais na distribuição da riqueza socialmente produzida e no uso e ocupação da terra.

Segundo Harvey (2009, p. 121),

[...] todas as características da acumulação primitiva que Marx menciona permanecem fortemente presentes na geografia histórica do capitalismo até nossos dias. A expulsão de populações camponesas e a formação de um proletariado sem terra tem se acelerado em países como o México e a Índia nas três últimas décadas; muitos recursos antes partilhados, como a água, tem sido privatizados (com frequência por insistência do Banco Mundial) e inseridos na lógica capitalista da acumulação; formas alternativas (autóctones e mesmo, no caso do Estados Unidos, mercadorias de fabricação caseira) de produção e consumo tem sido suprimidas. Indústrias nacionalizadas têm 
sido privatizadas. O agronegócio substituiu a agropecuária familiar. E a escravidão não desapareceu (particularmente no comércio sexual).

Essa longa citação revela a atualidade do debate marxista para a compreensão dos processos de mundialização do capital na busca por lucratividade. São práticas neoliberais, que alimentam a emergência de um novo urbanismo sob a perspectiva do capital, pelo qual as cidades, regidas pela mesma lógica das empresas, são objeto de acumulação capitalista (HARVEY, 2009).

No Brasil, segundo Mota (2007), esse modelo de desenvolvimento, antidemocrático, subalterno, à base de uma modernização conservadora, impediu a socialização da riqueza, do poder econômico e político, e tem servido para aumentar os privilégios de uma reduzida parcela da população brasileira. Trata-se de um modelo que impulsiona processos de banalização da questão social e implantação de políticas sociais focalizadas, de assistencialização e criminalização dos movimentos sociais, de sua anulação como sujeitos políticos e de sua destruição como classe (OLIVEIRA, 1999).

Em uma sociedade na qual os direitos inalienáveis à propriedade privada se sobrepõem a qualquer outra concepção de direito, a luta por cidades democráticas e justas é uma alternativa política. Está-se falando de uma sociedade na qual o mercado tem uma função distinta e sem precedentes: tudo na sociedade capitalista é mercadoria produzida para o mercado.

No Brasil, especialmente, onde $86 \%$ da população estão nas áreas urbanas, estas se constituem espaços nos quais a reprodução da vida social ocorre de forma profundamente desigual, sob os determinantes da especulação financeira e imobiliária, que transforma as cidades a partir dos imperativos da competição, da acumulação e da maximização do lucro (WOOD, 2001).

Assim, lutar pelo direito à cidade exige resistência e organização política com vistas a um projeto societário fundado na existência real e concreta da igualdade e da liberdade na vida de mulheres e homens, possibilitando-lhes acesso aos bens da civilização (IAMAMOTO, 2009).

O direito à cidade é um direito coletivo na construção de um sistema de proteção para viver dignamente, com acesso de todas 
e todos que nela habitam a tudo que a cidade pode oferecer para a reprodução da vida social, no reconhecimento da vontade coletiva, da convivência dos diferentes e no enfrentamento das contradições sociais. Conforme definição subscrita por vários organismos sociais, o direito à cidade é

[...] el derecho colectivo de las generaciones presentes y futuras para una ciudad sostenible sin discriminación de sexo, edad, raza, estado de salud, ingresos, nacionalidad, origen étnico, migración, orientación política, violencia sexual o religiosa, así como a preservar su identidad y la memoria cultural (HABITAT INTERNATIONAL COALITION, FÓRUM NACIONAL DA REFORMA URBANA, ALIANÇA INTERNACIONAL DOS HABITANTES, 2012).

O marco legal da reforma urbana no Brasil tem sua base instituída na Constituição Federal de 1988 (BRASIL, 1988), cujo capítulo que trata da política urbana define a função social da propriedade e da cidade, e reconhece a prevalência do interesse coletivo sobre o individual. Na trilha da ampliação da universalização dos direitos, a Emenda Constitucional $\mathrm{N}^{\circ} 26$, de 2000 , garante a moradia como parte dos direitos sociais e humanos, e o Estatuto da Cidade (Lei $\mathrm{N}^{\circ}$ 10.257), em 2001, regulamenta os artigos da Constituição Federal e define os instrumentos urbanísticos fundamentais para o cumprimento do direito à cidade (BRASIL, 2001).

Mas, se por um lado, as conquistas dos movimentos sociais e organizações populares colocaram no horizonte a possibilidade da construção de cidades democráticas, a reorganização do processo de produção e reprodução do capital, e a expansão liberal provocaram outro conjunto de respostas ao tema do direito à cidade, nas políticas e nos programas desenhados sob a marca do mercado, inclusive muitos deles regidos sob a influência dos organismos multilaterais.

Na perspectiva do marco legal, as instâncias de poder instituídas devem ter como diretriz uma política efetiva de ocupação do território brasileiro. Sob os parâmetros de um desenvolvimento urbano orientado por um pacto federativo, a ocupação do solo deve se efetivar na articulação entre o local e o nacional, requisitando intervenções econômicas, legais e físico-am- 
bientais, tendo em vista cidades que respondam às demandas de universalização dos direitos.

O que se observa nas cidades brasileiras é um descompasso com o estabelecido na Constituição Federal de 1988 e um descumprimento do que é orientado pelo Estatuto da Cidade, ainda que se tenha como entendimento que não se constroem cidades justas apenas com a arquitetura e urbanismo, nem tampouco com a aplicação arbitrária da lei (MARICATO, 2011a, p. 123).

Essa configuração política e econômica para a realização do capital, de crença na liberdade do mercado, de redirecionamento do papel do Estado, de reestruturação produtiva e de mudanças no mundo do trabalho, de "[...] políticas públicas, em suas conhecidas diretrizes de focalização, descentralização, desfinanciamento e regressão do legado dos direitos do trabalho [...]" mobiliza para algumas reflexões, num diálogo com a atuação do assistente social (IAMAMOTO, 2009, p. 26).

Assim, tendo em vista a crítica às determinações da sociabilidade do capital elaborada a partir de subsídios teóricos retirados de análises clássicas e contemporâneas do pensamento crítico, este texto pretende apontar, a partir da matriz da política urbana no Brasil, características e aspectos de sua efetivação, discutindo as determinações e mediações que possibilitam contemplar a diversidade social e econômica da população brasileira, e suas contradições, na luta contra a mercantilização da terra e na defesa do direito à cidade.

Além disso, pretende indicar possíveis respostas para uma questão que é colocada como diretriz de trabalho: "Contra o esvaziamento e a transformação da política em espetáculo e contra a reatualização do conservadorismo, assistencialização da pobreza e criminalização dos movimentos sociais, é possível construir formas de resistência e reforçar o compromisso profissional por trabalho, direitos e liberdade?" (SANTOS; BOSCHETTI, 2011).

O artigo está estruturado em três partes: inicialmente, discute-se a tensão entre projeto de desenvolvimento do capital e as contradições da expansão do Brasil urbano, ressaltando o significado sócio-histórico do direito à cidade; a seguir, a partir das particularidades da política urbana, busca-se destacar os mecanismos para sua efetivação e as expressões de suas contradições; por fim, a título 
de conclusão, alinhavam-se alguns elementos que possam vir a alimentar estratégias políticas profissionais.

\section{NO CONTEXTO DO CAPITAL: O DIREITO À CIDADE}

Conforme Lefèbvre (1991, p. 4), a cidade preexiste à industrialização. Nas suas palavras, "[...] houve a cidade oriental (ligada ao modo de produção asiática), a cidade arcaica (grega ou romana, ligada à posse dos escravos), depois a cidade medieval [...] principalmente comercial, artesanal, bancária".

Mas, para se entender o papel do desenvolvimento urbano, especialmente sob as condições das relações sociais capitalistas e da acumulação do capital, é interessante pontuar alguns aspectos do debate sobre os processos de urbanização e da expansão das cidades, em suas raízes históricas, fincadas desde a primeira metade do século XIX, ainda na fase concorrencial do capitalismo, com a grande indústria provocando o crescimento urbano, de criação de um mercado mundial e de deslocamento da presença visível da pobreza (HARVEY, 2005). Nesta fase, os trabalhadores ficavam à mercê de seus patrões e o Estado garantia a manutenção da propriedade privada e da ordem pública.

A partir da segunda metade do século XIX, esse quadro irá mudar, em função das lutas operárias, do desenvolvimento das ciências naturais, do surgimento dos monopólios e do novo papel dos bancos. É importante acentuar o papel que cumpre o Estado, na função de administração das crises com políticas voltadas para evitá-las, proporcionando garantias econômicas aos processos de valorização e acumulação do capital. O agravamento da exploração e da desigualdade dela indissociável produz o crescimento de enormes segmentos populacionais excluídos do círculo da civilização com alternativas que vão da solidariedade à violência nos espaços urbanos.

Segundo Hobsbawn (1995), o período entre a Primeira e Segunda Guerra Mundial foi marcado por tempos sombrios, quando várias crises do capital se manifestaram, colocando a necessidade da intervenção do Estado na economia capitalista. Esse cenário é assim explicado por Netto e Braz (2006, p. 195),

[...] seja no nível dos investimentos, estimulando-os diretamente (inclusive com o Estado operando 


\begin{abstract}
como empresário capitalista em setores-chave da economia), seja no tocante à reprodução da força de trabalho, desonerando o capital de parte de suas despesas (através de programas sociais tocados por agências estatais).
\end{abstract}

Após a Segunda Guerra Mundial, há um redimensionamento do papel do Estado que passa a intervir ativamente na economia e na política para a acumulação capitalista. Nesse período, as contradições próprias dos embates entre as classes sociais obrigaram o Estado a reconhecer os direitos sociais. Notadamente em países do capitalismo central, configura-se o estado do bem-estar que busca compatibilizar a dinâmica da acumulação e da valorização do capital com a garantia dos direitos políticos e sociais mínimos.

Essa dinâmica muda radicalmente a partir dos anos 1970 e, com o objetivo de enfrentar mais uma crise do modo de produção capitalista, transformam-se em formas de intervenção do governo a privatização e a liberação do mercado, "[...] revertendo as conquistas sociais alcançadas no segundo pós-guerra" (NETTO; BRAZ, 2006, p. 206). Ainda segundo esses autores, no lugar da incorporação das demandas dos trabalhadores, da "[...] consolidação das políticas sociais e a ampliação de sua abrangência [...]", da produção de conjuntos habitacionais, do investimento em infraestrutura, de intervenção do Estado no mercado de terras, os objetivos das políticas e função do Estado passam a ser o incentivo de processos de desvalorização da força de trabalho e de ativos do capital, de fortalecimento do planejamento e redução da intervenção nos conflitos sociais, de gestão e gerenciamento de fluxos e controle contábil, com ênfase nas ações que favorecem a especulação imobiliária (NETTO; BRAZ, 2006, p. 206). Os argumentos de Harvey (2009, p. 130-131) corroboram com essa afirmativa.

Ativos de propriedade do Estado ou destinados ao uso partilhado da população em geral foram entregues ao mercado para que o capital sobreacumulado pudesse investir neles, valorizá-los e especular com eles [...]. No caso de Thatcher, o grande estoque de habitações sociais foi um dos primeiros ativos a ser privatizados. 
A referência de Wood (2001, p. 112) sobre o desenvolvimento do sistema capitalista contribui para a compreensão desse processo.

[...] é desnecessário dizer que o sistema capitalista está em constante estado de desenvolvimento e fluxo. Mas não compreenderemos seus processos atuais de mudança e contradição se não soubermos rastreá-los até suas bases [...] A transformação específica das relações sociais de propriedade que acionou um 'progresso' historicamente singular das forças produtivas não pode ser presumida como um dado. Reconhecer isso é crucial para a compreensão do capitalismo - para não falar na compreensão das condições de sua abolição e sua substituição por uma forma social diferente.

No Brasil, essa dinâmica apresenta características singulares. Portanto, a remissão pontual a eventos econômicos e políticos do Brasil de meados do século $X X$ até a atualidade contribui para o entendimento da funcionalidade do capitalismo brasileiro que orientou o crescimento das cidades e o processo de urbanização.

$\mathrm{Na}$ direção de um Estado que expressa os interesses dominantes, o Brasil urbano é construído sob as diretrizes da burguesia internacional e frações da burguesia nacional. Efetiva-se uma modernização incompleta e excludente que alimenta a acumulação urbana, na produção de moradias, na implantação de obras públicas, na concessão de serviços, sob o predomínio de um Estado autoritário e corporativo.

A integração brasileira ao Capitalismo internacional resultou em um desenvolvimentismo subordinado desde os anos 1950, o qual tem respaldo nas "[...] metas econômicas do governo federal (que) não só conviveram com precárias condições de vida da maioria da população brasileira, como ainda permitiram ocultá-las" (VIEIRA, 1983, p. 27).

A repressão política, com concentração da propriedade territorial e expropriação dos trabalhadores, características de uma modernização conservadora junto com o milagre econômico, arrocho salarial e aumento da dívida externa, nas duas décadas seguintes, é o cenário para o programa habitacional financiado pelo Banco Nacional de Habitação que, na década de 1960, muito contribuiu para definir o projeto urbano do país (IAMAMOTO, 2007; NETTO, 1991; VIEIRA, 1983). 
A década de 1970 redescobre a política em plena crise da Ditadura. As classes populares, trabalhadores e movimentos sociais começam a se identificar como sujeitos políticos a partir da resistência cotidiana e as demandas sociais chegam ao Estado. Segundo Kowarick (2000, p. 34),

[...] é conveniente ressaltar de imediato que, além das reivindicações e conflitos que decorrem do processo de exploração do trabalho e de espoliação urbana, muitos são os grupos que se organizaram em torno de uma gama variada de demandas, entre as quais se destacam o movimento feminista e o das minorias raciais, principalmente os negros, que procuram colocar em xeque uma situação secular de subalternidade, exclusão e preconceitos de várias ordens e matizes.

Com o fim do governo ditatorial, nos anos 1980, vê-se a articulação do poder econômico com a restituição do estado democrático e outra cultura política começa a tomar forma, no desenho de uma sociedade que busca se materializar na perspectiva da democracia, dos direitos e da cidadania. O pacto Tudo pelo Social propõe-se a responder a uma dívida social do país com os pobres, como tentativas malsucedidas de esvaziamento das mobilizações sociais. Há uma difícil transição política, porque, no nível internacional, o arranjo global do Capitalismo afirma uma modernidade nos pilares do Neoliberalismo.

As crises macroestruturais rebatem nas ainda frágeis reorganizações das classes trabalhadoras que, mobilizadas para o processo de participação, abrem o caminho da democracia pela possibilidade de construção de instituições democráticas. Nos anos 1990, a economia se redefine, agora sob os imperativos do capital financeiro e do Neoliberalismo, da privatização e descentralização, que se traduz em municipalização, e da eficiência de um Estado que assume o papel de administrador (MOTA, 2007; PAULANI, 2008). O pacto neoliberal aprofunda a crise do desenvolvimento do Estado da social democracia. O desemprego amplia seu quadro, o sindicalismo transmuta-se em sindicalismo de resultados. São projetos societários em disputa. Ainda nos anos 1990, o Capitalismo começa a implodir vários conceitos que ousam colocar em questionamento sua hegemonia, como democracia, direitos e participação. 
Para intensificar o processo produtivo, desde os últimos 60 anos, estimulou-se o movimento migratório, primeiramente, Norte-Sul e, posteriormente, campo-cidade. Esse rápido percurso na história mostra que, em pouco mais de quatro décadas, o país deixa de ser rural para tornar-se, predominantemente, urbano, com índices sociais reveladores de uma enorme desigualdade social, numa combinação complexa cujos atributos constitutivos apresentam aspectos patrimonialistas, clientelistas e paternalistas (KOWARICK, 2009). A lógica que move esse crescimento é empreendedorista, reduzindo as relações sociais estabelecidas nas cidades sob esses aspectos determinantes para o exercício do poder, a mera forma de gestão da cidade.

Atualmente, 60\% da população urbana vive em 224 municípios com mais de 100.000 habitantes, dos quais 94 pertencem a aglomerados urbanos e regiões metropolitanas com mais de um miIhão de habitantes (ROLNIK, 2008). Além disso, a maioria das cidades brasileiras que tem até 50.000 habitantes conta com dificuldades de ordem financeira e de capacidade gerencial, o que fermenta desigualdades que alimentam processos clientelistas e que respondem aos interesses do capital e a seus organismos multilaterais (Fundo Monetário Internacional, Banco Interamericano de Desenvolvimento e Organização Mundial do Comércio) pela capacidade de interferir na soberania dos municípios.

As mudanças ocorridas nas últimas décadas no modo de ser da classe trabalhadora incidiram diretamente na dimensão política da sua consciência de classe. Do que foi exposto anteriormente, apreende-se o movimento da crise estrutural do capital que, por um lado, revela os limites do capital e, por outro lado, vale-se de discursos conservadores e de mecanismos de cooptação e domesticação para promover a limitação também da liberdade e da autonomia dos trabalhadores no acesso às necessidades humanas básicas. Nessa direção, o ideário disciplinador neoliberal, que reestrutura o capital na sua relação com o trabalho, redireciona as organizações políticas na perspectiva de um projeto de sociedade de caráter reformista, para o que contribui o "[...] cenário de desemprego, precarização do trabalho, aumento da informalidade e privatizações" que trouxeram dificuldades ao processo de luta por condições dignas de vida dos trabalhadores (AMARAL, 2007, p. 111). 
A doutrina neoliberal e a aplicação de seu receituário de política econômica veem diminuída sua área de influência diante da ideia agora defendida de um Capitalismo sério, produtivo e democrático (MOTA, 2010). Por dentro mesmo do ideário de desenvolvimento, o discurso está modificado. A palavra de ordem é desenvolvimento com crescimento econômico e equidade. Trata-se de um neodesenvolvimentismo que nada tem a ver com o antigo desenvolvimentismo. O que se observa é a presença de um estado forte que investe na construção de infraestrutura econômica e social, e atua na ampliação de conglomerados brasileiros privados para torná-los competitivos no mercado internacional (MARICATO, 2011a).

Nas palavras de Maranhão (2010), sob a orientação de Amarthya Sen, o ideólogo que busca compatibilizar crescimento econômico capitalista com o desenvolvimento humano e social sob a lógica do mercado, regulador supremo da vida social e mediado pelo Estado para garantir o acesso aos benefícios do mercado, vê-se emergir um novo desenvolvimentismo. Na crítica de Mota, Amaral e Peruzzo (2010, p. 53), trata-se de um modelo que se respalda na ideologia do "[...] empreendedorismo, dos negócios próprios, da necessidade de acumular um capital social robusto para ter acesso a outros recursos, da sustentabilidade [...]", das oportunidades e liberdade de escolha individual.

Trata-se de uma concepção de desenvolvimento social e econômico que tem como princípio aliar crescimento econômico com o combate à pobreza, com o desenvolvimento humano e a sustentabilidade, reforçando escolhas individuais e mobilizando as pessoas para desenvolverem suas capacidades no sentido de se inserirem no mercado, concepção essa na qual as políticas públicas são um complemento do mercado e não uma proteção contra os efeitos negativos deste (MARANHÃO, 2010). É a defesa de um progresso que oculta os antagonismos sociais, aumenta as violências institucionais e aprofunda as injustiças sob as premissas da regulação da gestão (CASTEL, 2009).

Os organismos internacionais vêm pautando esse debate no reconhecimento de que o mercado não alterou o quadro da desigualdade e pobreza mundial, que o Estado não pode suprir 
as deficiências do mercado, que as metas do milênio não serão atendidas até 2015 (MOTA, 2007). Na agenda desenhada por esses organismos, a ênfase está na participação e nas políticas de proteção social como manejo de risco, sob a lógica do mercado e não sob a lógica de orientações políticas. Como grandes incentivadores desses processos, eles influenciam e fomentam a despolitização dos diferentes segmentos sociais, na ênfase na organização de grupos de interesses, no incentivo às comunidades para buscarem individualmente as respostas aos seus problemas, nas respostas ideológicas de solidariedade, no fortalecimento da família e na negação dos conflitos de classe.

Conforme Paulani (2008), um plano de desenvolvimento para o Brasil passaria pela capacidade de o país fazer política econômica, o que implicaria vontade política de alterar o modelo atual.

Sabe-se que, sob os parâmetros do capitalismo, o problema da moradia nunca será resolvido, já o afirmou Engels (1987) ao discutir a questão da habitação. Todavia, é preciso ampliar o conhecimento da realidade, buscar elementos na história para discutir novas experiências para alimentar a esperança e a ação transformadora, para reafirmar o diálogo necessário entre a economia e a política, a economia e o social, cujas articulações possibilitam um desenvolvimento econômico e social sem precedentes (MARICATO, 2011a).

\section{A CONSTRUÇÃO DA POLÍTICA URBANA: ESTADO E MOVI- MENTOS SOCIAIS E O DIREITO À CIDADE}

A agenda institucional da política urbana tem sua sustentação ideopolítica na defesa de cidades justas e igualitárias. E mais, é necessário ter presente a produção material da vida e a participação da força de trabalho para analisar os processos de luta contra a concentração da renda e da terra, com vistas a uma sociedade democrática. Conforme Vieira (2004, p. 134-135, grifos do autor),

Criar uma 'sociedade do bem-estar', sem dar a todos participação efetiva no controle das decisões e também nos rendimentos da produção, consiste unicamente na adoção dos homens para transformá-los em consumidores obedientes e bem humorados [...]. Participar dos rendimentos da produção envolve não 
só mecanismos de distribuição de renda, mas, sobretudo, níveis crescentes de coletivação das decisões, principalmente nas diversas formas de produção.

Para reforçar o pensamento na defesa de uma sociedade democrática, tomou-se por base um dos princípios do código de ética profissional dos assistentes sociais que define democracia, entendida como padrão de organização política capaz de favorecer a ultrapassagem das limitações reais que a ordem burguesa impõe ao desenvolvimento pleno da cidadania, dos direitos e das garantias individuais e sociais, e das tendências à autonomia e à autogestão social (CONSELHO FEDERAL DE SERVIÇO SOCIAL, 2012).

Tendo em vista esses conceitos de sociedade democrática, cabe aguçar a crítica dos fundamentos sobre os quais se baseou a matriz da política urbana e acrescentar que as cidades brasileiras nunca tiveram um projeto estratégico que envolvesse as diferentes dimensões do desenvolvimento urbano, com integração das políticas setoriais (habitação, mobilidade urbana, saneamento básico, planejamento e gestão do solo com acesso a terra urbanizada e regularizada), ao lado de estratégias de enfrentamento da valorização da propriedade fundiária e imobiliária.

Segundo Maricato (2011a, p. 123), a base modernista-funcionalista que norteou o planejamento urbano brasileiro “[...] contribuiu para a que a cidade brasileira fosse marcada pela modernização incompleta ou excludente".

A presença do Estado na questão habitacional brasileira teve início nos anos 1930, com programas que privilegiavam pequena parcela da demanda, deixando a maioria sujeita a buscar, num mercado especulativo, soluções frequentemente caracterizadas pela precariedade ou informalidade. Mesmo no período do Banco Nacional de Habitação (de 1964 a 1984), quando os recursos para financiamento foram fartos e a produção conseguiu atingir uma dimensão massiva, não se logrou viabilizar formas de atender a maior parte da população, que participava do expressivo processo de urbanização do período.

A questão da democracia para o Estado brasileiro tem tido como objetivo o referendo das suas propostas com uma lógica particularista, que funciona segundo interesses de cunho clientelista, pa- 
trimonialista e corporativista. Como se pode exemplificar com as resoluções aprovadas no Conselho Nacional das Cidades (CONClDADES) sobre os programas: Programa de Aceleração do Crescimento (PAC) e Programa Minha Casa Minha Vida (PMCMV), e conforme Relatório do Observatório das Metrópoles (2011)4.

Uma análise da atuação do CONCIDADES possibilita ver os desafios que estão postos na representação e na dificuldade da partiIha do poder, e os interesses particulares presentes na defesa do interesse público. Nas três gestões do Conselho, até o ano de 2011, observa-se uma diminuição do número de resoluções discutidas e um número significativo de resoluções sem efetividade. São temas ausentes do debate: os programas Minha Casa Minha Vida e PAC, questões orçamentárias e a política nacional de desenvolvimento urbano (MARICATO e SANTOS JR., 2006).

Com base no relatório citado, durante três gestões do CONCIDADES, foi recorrente a ausência da discussão dos seguintes temas: orçamento da Secretaria Nacional de Políticas Urbanas e do Ministério das Cidades; a Política Nacional de Desenvolvimento Urbano; o monitoramento da implementação do PAC e do PMCMV, e seus impactos no desenvolvimento das cidades; as políticas sociais afirmativas de gênero e raça; a ausência de resoluções envolvendo alocação de recursos e política econômica. Nesse sentido, como afirma Vieira (2004, p. 142),

Não se pode analisar a política social sem se remeter à questão do desenvolvimento econômico, ou seja, à transformação quantitativa e qualitativa das relações econômicas, decorrente de processo de acumulação particular do capital. O contrário também precisa ser observado: não se pode examinar a política econômica sem se deter na política social.

\footnotetext{
${ }^{4}$ As resoluções que se referiram ao FNHIS e ao Conselho Gestor tiveram efetividade, com exceção das duas que previam a alocação de R\$ 3 bilhões ao FNHIS. Ver no site do Ministério das Cidades. O PAC praticamente não foi objeto de

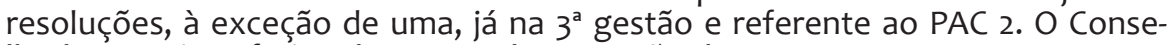
lho buscou interferir sobre a regulamentação do programa MCMV, mas as resoluções sobre esse ponto tiveram pouca ou mesmo ausência de efetividade. A baixa efetividade se refere basicamente à não complementação do processo de discussão do PLANHAB e às mudanças na operação da política habitacional advindas do lançamento do programa Minha Casa Minha Vida e PAC.
} 
É importante lembrar algumas determinações que tem contribuído para alterar a face da política urbana na sociedade brasileira. Em meados da primeira década do século XXI, tem-se o ideário de um novo paradigma da política urbana, principalmente o de não desvincular a política habitacional da política fundiária (MARICATO, 2011a). Mas esta proposta original se perde; na implantação da política urbana, o velho patrimonialismo brasileiro venceu. O Ministério das Cidades é esvaziado da elaboração e execução da política, e as orientações são emanadas de um Banco (Caixa Econômica Federal) e do Ministério do Planejamento, que concentra o desenho do que se tornou a política urbana.

A título de exemplo, cabe registrar que a política de habitação foi de responsabilidade de diferentes ministérios nas últimas décadas: de 1985 a 1987, do Ministério do Desenvolvimento Urbano e Meio Ambiente; de 1987 a 1988, do Ministério da Habitação, Urbanismo e Meio Ambiente; de 1988 a 1990, do Ministério do Bem-Estar; de 1990 a 1995, do Ministério da Ação Social; de 1995 a 1999, da Secretaria de Política Urbana, vinculada ao Ministério do Planejamento; de 1999 a 2002, da Secretaria Especial de Desenvolvimento Urbano, vinculada à Presidência da República, mudanças que expressam as diferentes leituras da questão urbana, tanto políticas quanto ideológicas e que, historicamente, impactam na vida das classes trabalhadoras.

Em 2003, foi criado o Ministério das Cidades. A partir daí, saneamento e mobilidade urbana passam a fazer parte do sistema, além da política de habitação, mas apresentam um processo mais lento de respostas às demandas da sociedade brasileira. $\mathrm{O}$ marco regulatório do saneamento básico foi aprovado em 2007 e o da mobilidade urbana, em 2011 e, mesmo assim, como se pode verificar nas decisões do CONCIDADES, observa-se a ausência dessa discussão e aprovação de resoluções referentes às temáticas. ${ }^{5}$

\footnotetext{
5 Em junho de 2011, foi realizada, em Brasília, uma oficina de capacitação dos novos conselheiros do CONCIDADES. Foram elaborados diversos documentos analíticos para apresentar o estado da arte das políticas setoriais urbanas. Entre esses documentos, destaca-se o Relatório do Observatório das Metrópoles, que, sob a coordenação de Orlando Alves dos Santos Jr. (IPPUR/UFRJ), Adauto Lucio Cardoso (IPPUR/UFRJ) e Regina Ferreira (IPPUR/UFRJ), apresentou o monitoramento das resoluções emitidas pelo CONCIDADES, o que possibilitou verificar a capacidade decisória e a efetividade desse.
} 
O saneamento básico é determinante na qualidade da moradia. A população que tem acesso aos serviços de saneamento é menos vulnerável a doenças associadas à provisão deficiente de saneamento, tais como infecções diarreicas (principal causa de morte em crianças até cinco anos), infecções parasitárias, dengue, leptospirose. Todavia, conforme Cordeiro, Brito e Pereira (2011, p. 18), “[...] apesar do reconhecimento de um avanço na construção de uma regulamentação orientada pela perspectiva do saneamento como direito, alertamos para a preponderância do poder corporativo nos processos de tomada de decisão do setor de saneamento".

Assim, refletir sobre o direito à cidade e as estratégias de lutas e reivindicações com vistas ao acesso a esse direito no Brasil é refletir sobre a história da participação política das classes populares que apresenta elementos singulares em nosso país. Mesmo porque, o que a história registra é que as arenas participativas pouco influem nos processos decisórios.

Na realidade, são várias as dificuldades para o exercício cotidiano da participação coletiva e das lutas dos movimentos sociais, que vão desde a presença de estruturas de participação débeis até a mediação do Estado, "[...] induzindo relações de dependência e subordinação, pelo fracionamento dos grupos sociais em busca de privilégios" (RAICHELIS, 1998, p. 180).

As conferências nacionais realizadas até hoje mostram, pelos debates e encaminhamentos pactuados, a diversidade das leituras políticas dos diferentes segmentos sociais sobre o direito à cidade. A $1^{\text {a }}$. Conferência, realizada em 2003, aprofundou o significado do direito à moradia digna, além de discutir o plano nacional de desenvolvimento urbano. A $2^{\text {a }}$. Conferência, em 2005, debate o desenho da política nacional de desenvolvimento urbano numa perspectiva de integração das políticas setoriais. A $3^{a}$. Conferência, em 2007, apresenta para discussão a proposta de criação de um sistema nacional de desenvolvimento urbano (SNDU). A 4 a . Conferência, realizada em 2010, não avança politicamente no sentido de discutir o SNDU, mas debate o cumprimento do Estatuto da Cidade, mesmo porque, passados 10 anos de sua aprovação, a não implementação dos instrumentos ali 
desenhados apontam que não se estabeleceu como meta enfrentar a questão urbana6.

Outros elementos agregam informações a essas reflexões sobre a política urbana e seu significado político no contexto do Estado brasileiro e da sociedade civil. O Plano Nacional de Habitação (PLANHAB), finalizado em 2009 e aprovado no Conselho das Cidades, tem sua implementação atropelada pelos programas governamentais Minha Casa Minha Vida e Programa de Aceleração do Crescimento, cujos projetos respondem aos interesses do capital, e, muitas vezes, revelam inadequação das intervenções físicas e das soluções habitacionais, seja nas ações higienistas e na ausência de diálogo e da participação social da população envolvida, seja nas remoções provocadas e na violência dos despejos.

Apesar de todo aparato legal existente, a propriedade fundiária e imobiliária continua a fomentar a desigualdade social e urbana (MARICATO, 2011b). A efetivação dos instrumentos legais da política urbana (Estatuto da Cidade, Planos Diretores Participativos, PLANHAB, Planos Locais de Habitação de Interesse Social), que defendem cidades justas sob os pressupostos da liberdade e da igualdade, pode estar na Carta de 1988 e nos instrumentais legais regulatórios posteriores, mas não tem se traduzido em políticas sociais de alcance massivo. Acresce-se a isso outro aspecto a ser considerado, que afeta a potencialidade da cultura política do direito à cidade: as Emendas Parlamentares, estrutura institucional legislativa que alimenta vínculos clientelistas e patrimonialistas, ao determinar investimentos pontuais que acabam por interferir na efetivação da política urbana nos municípios brasileiros.

Segundo lamamoto (2007), é no terreno de disputas, na tensão entre a reprodução da desigualdade e produção da resistência que vêm ocorrendo avanços na construção e promoção de espaços de diálogo, concertação e democratização da política urbana brasileira.

Vivem-se tempos duros explicitados na tragédia urbana brasileira sob o desenvolvimento das forças produtivas e das relações sociais de produção capitalista - enchentes, desmoronamentos, poluição

\footnotetext{
${ }^{6}$ A partir das análises realizadas por Maricato e Santos Jr, registra-se que Arlete Moysés Rodrigues (UNICAMP-SP), em 2011, avançou nas reflexões sobre o exercício político das Conferencias Nacionais.
} 
dos recursos hídricos, poluição do ar, impermeabilização da superfície do solo, desmatamento, reincidência de epidemias, violência, aos quais se somam as remoções e os descartes de populações inteiras porque o capital não pode incluí-las no processo de reprodução (MARICATO, 2001).

Assim, deve-se ter clara a necessidade de inverter algumas lógicas que foram construídas a partir de um modelo de cidade e de serviços com base na mercantilização e na espoliação: do transporte como mercadoria, para seu acesso universal; do saneamento como gasto, para investimentos necessários à sociedade brasileira; e da moradia como bem, para serviço essencial.

\section{SERVIÇO SOCIAL E O DIREITO À CIDADE}

No papel de sujeitos coletivos qualificados, o grande desafio dos assistentes sociais, na defesa do direito à cidade, é desenvolver análises críticas e interpretar, sistematicamente, os complexos processos sociais, apreendendo suas determinações objetivas e subjetivas em relação às práticas sociais. Além disso, deve desvelar a crescente opacidade construída pelo uso de determinados conceitos, deslocados de seu sentido original e resignificados pelo projeto neoliberal, o que tornou a disputa política entre projetos muito distintos em uma aparente disputa de significados para referências comuns, como participação, sociedade civil ativa, etc. A homogeneização de vocabulários permitiu obscurecer diferenças: à expectativa de uma sociedade civil ativa e propositiva, disputada pelas agências financiadoras internacionais e incorporada por governos de diferentes matizes políticos-ideológicos se conjuga, por vezes, a concepção de sociedade civil como sujeito de cooperação; abstraindo das relações entre Estado e sociedade, os conflitos e a disputa entre projetos de classe.

A perspectiva de ampliação dos espaços democráticos para tomada de decisões como forma de diminuir as distâncias sociais por meio da política é substituída pela abordagem da participação como dependente do chamado capital social - quanto mais associativa for uma localidade, mais concessões entre indivíduos e o coletivo, mais redes sociais de cooperação instituídas, mais capital social se observa naquele grupo social. O acúmulo de capital social empoderaria os setores até então excluídos, tirando-os dessa condição. 
Outro aspecto a ser desvelado é que a consensual defesa da participação ocorre, na melhor das hipóteses, com relação à gestão de segmentos da política urbana - saneamento, habitação e desenvolvimento urbano - sem articulação macroestrutural entre esses segmentos. Mais do que isso, não entra na pauta de debates a abertura de espaços participativos em relação às definições da política econômica que, de fato, é o que determina grande parte dos problemas vividos pelas cidades (MARICATO; SANTOS JR, 2006).

Maricato (2011b) também aponta o fato de se ter adentrado num processo de participativismo, ou mesmo no ativismo das demandas fragmentadas, com objetivos mais imediatistas e respaldado em interesses singulares.

Com isso, não se quer definir como menos importante as conquistas de reivindicações concretas, relacionadas à pauta de acesso ao direito à cidade; essas representam o alimento essencial para qualquer movimento reivindicatório de massas, e nada mais são do que parte do resgate de dívidas da segregação socioeconômica e, consequentemente, urbana.

São outros os obstáculos à democracia social. As disputas acabam por ocorrer em torno do poder de governar, portanto, na esfera da administração de políticas fragmentadas, enquanto o poder de, efetivamente, definir os usos e a ocupação dos espaços urbanos permanece na esfera dos agentes do mercado que, de fato, determinam os parâmetros de produção e apropriação desse.

Esse é, portanto, um momento de impasse da política urbana no Brasil, só superável na medida em que se consiga elucidar "[...] a estratégia das formas selvagens que fazem do solo urbano e dos orçamentos públicos pasto para seus interesses" (MARICATO, 2011b, p. 78). E, a partir da identificação das forças que tem poder sobre a produção das cidades, incidir para a mudança de rota na qual a defesa da função social da cidade é fundamental (MARICATO, 2011b).

Como sujeitos coletivos qualificados, cabe ao assistente social desvelar o sentido ideológico de expressões como desenvolvimento e comunidade; compreender o uso de mecanismos de atendimento diferenciado aos ocupantes de áreas não regula- 
res, de acordo com o tempo de ocupação - restando, no mais das vezes, uma promessa de atendimento apenas aos ocupantes antigos e, aos novos, a classificação de oportunistas, sem qualquer referência à compreensão dos processos históricos que levaram a essas ocupações; enfim, quanto mais os assistentes sociais forem capazes de decifrar e apreender as determinações da produção e reprodução das cidades, mais terão condições para elaborar respostas proffissionais qualificadas, teórico, política e eticamente.

Faz-se aqui uma ressalva: no campo da política urbana, o trabalho do assistente social acaba por se efetivar na área das políticas habitacionais - com alguma interface com o saneamento - e não nos demais setores da política. Nesse campo, as demandas postas aos assistentes sociais, na atualidade, são requisições técnicas operativas que incorporam exigências de gestão da pobreza, e não do seu combate e erradicação; é a implementação de políticas com funções compensatórias como alternativas estratégicas à crise, que não estão associadas a políticas de emprego e, tampouco, à universalização dos direitos sociais.

Aos trabalhadores sociais se exige que sejam polivalentes e capazes de se adaptarem às mudanças, de serem proativos e criativos nas iniciativas de trabalho, apesar de os contratos precários de trabalho se efetivarem, muitas vezes, por projetos, com um vínculo muito tênue de responsabilidade entre o empregador e o empregado, não dispondo o profissional de um mínimo de segurança e proteção, muito menos de direito à formação.

Por outro lado, as diretrizes do trabalho social são impregnadas da lógica da administração empresarial, nas exigências de gerenciamento e nos padrões normativos de gestão, e na proposição de práticas que, supostamente, estariam voltadas para superar os gargalos da burocracia pública.

Essas reflexões alimentam o pensamento sobre os principais desafios para concretização do Projeto Ético Político do Serviço Social: as condições objetivas do trabalho profissional precisam ser problematizadas, no quadro da desregulamentação do trabalho a que estão submetidos os trabalhadores contemporâneos. Assim como a lógica do sistema produtor de mercadorias vem convertendo a concorrên- 
cia e a busca da produtividade num processo destrutivo que tem gerado uma imensa sociedade dos excluídos e dos precarizados, também os assistentes sociais, que vendem sua força de trabalho em troca de salário, estão submetidos aos dilemas e constrangimentos comuns a todos os trabalhadores assalariados (ANTUNES, 2000).

A expansão de formas de trabalho precário (trabalhos terceirizados, cooperativismo, e trabalhos submetidos a contratos temporários, sem estabilidade e registro na carteira) no interior do campo urbano, vem alimentando uma destrutividade intensiva do trabaIhador assistente social e da autonomia relativa do profissional, o aumento das competências e responsabilidades ao lado da flexibilização do trabalho, da jornada e da remuneração (ANTUNES, 2000).

Na mesma medida, a redução da dimensão criativa do trabalho se expressa na exigência do trabalho profissional para preencher fichas cadastrais para elaborar o perfil da população, ou, por outro lado, para orientar a população sobre a necessidade das remoções e dos despejos, na exigência de respostas ao imediato e ao cotidiano. As dificuldades para o desenvolvimento do trabalho social são identificadas não no universo da precarização do trabalho, mas na falta de integração das equipes social e de engenharia, na qualidade da equipe técnica, no pouco tempo disponível para o desenvolvimento do trabalho ao lado da descontinuidade pelo atraso ou paralização das obras.

Segundo Antunes (1999), são processos que, cumprindo um papel de funcionalidade em relação ao sistema, que não quer ter preocupação pública e social com os trabalhadores, alimentam o individualismo, e contribuem para tornar cada vez mais difícil as reivindicações e lutas coletivas dos assistentes sociais e, mais ainda, o diálogo com as lutas mais amplas da classe trabalhadora (RAICHELIS, 2011).

Assim como Mota (2010, p. 31), “[...] entendemos que os limites da autonomia técnico-profissional não se confundem com as possibilidades de construção de uma consciência crítica das relações que marcam a inserção dos assistentes sociais no mundo do trabalho profissional".

Na direção do projeto ético-político, o trabalho social na defesa do direito à cidade, à moradia digna, defronta-se, portanto, com 
perspectivas teóricas distintas: uma que compreende a ação profissional a partir de uma dimensão de totalidade, de caráter histórico-ontológico, remetendo o particular ao universal, e incluindo as determinações objetivas e subjetivas dos processos sociais; outra, que compreende a ação profissional como um campo de fragmentos, restrita às demandas do mercado de trabalho, cuja apreensão requer a mobilização de um corpo de conhecimentos e técnicas que não permite extrapolar a aparência dos fenômenos sociais.

Deriva destas afirmativas algumas conclusões: a primeira refere-se à importância de se ter uma visão histórico-processual da realidade. O que significa dizer que se devem identificar os limites dados pela estrutura econômica capitalista, e, no mesmo movimento, alimentar a convicção de que todas as coisas e todas as ideias se movem, se transformam e se desenvolvem, porque são processos. Mas só se tornam processos pela ação de homens e mulheres, sujeitos históricos capazes de transformar a história.

Nesse sentido, apreende-se uma segunda conclusão: é preciso acreditar na capacidade e potencialidade profissional e ético-política de intervir na realidade e não sucumbir ao desencanto e conformismo.

O que coloca uma terceira conclusão: a dimensão estratégica de viabilização do projeto ético-político passa por uma postura profissional que articula as lutas pela radicalização da democracia com o fortalecimento dos movimentos sociais da classe trabalhadora. Trata-se de um exercício político que deve acontecer a par das atividades cotidianas da intervenção profissional.

São reflexões que se somam à defesa que se faz da necessidade e importância de somar forças às lutas dos movimentos sociais e da sociedade civil organizada e compromissada na pressão para a implementação de uma agenda urbana comprometida com os direitos sociais definidos na Constituição Federal de 1988 e que reverta o quadro de segregação e pobreza nas cidades.

Nessa perspectiva, pode-se registrar que os movimentos e as organizações não governamentais de apoio às lutas populares desenvolveram uma gama de estratégias para incidir na estruturação da política urbana, entre as quais a inserção nas estruturas institucio- 
nais de participação, mas vem passando por um processo de reinvenção desses formatos. Destaca-se, aqui, a organização dos Comitês Populares da Copa, estruturados em cada uma das cidades que sediarão o evento, como exemplo dessa redefinição de formatos.

Em contraponto aos Comitês Organizadores Locais - dos quais fazem parte apenas representantes dos governos estadual e municipal, segmentos da sociedade ligados aos movimentos sociais, universidades, instituições de pesquisa e organizações não governamentais iniciaram a articulação de comitês populares locais, por sua vez, representados na Articulação Nacional de Comitês Populares (ANCOP). Participam entidades com perfis muito diversos, algumas das quais envolvidas na defesa de direitos humanos em geral, outras com pautas de ação mais específicas (por exemplo, mulheres, moradia, trabalho informal, tráfico de pessoas); outros, só recentemente, incorporaram a pauta do desenvolvimento urbano e das remoções de moradias nas suas agendas.

Em princípios de 2012, a ANCOP organizou o Dossiê Megaeventos e Violação de Direitos Humanos no Brasil, baseado num conjunto de informações fornecidas pelos Comitês Populares Locais sobre os direitos humanos nas várias cidades que sediarão o evento, relacionadas tanto com a expectativa de impactos quanto com aqueles impactos já vivenciados. Esses impactos focam os temas da moradia, do trabalho, da informação, da participação e da representação popular, do meio ambiente, do acesso a serviços e bens públicos, da mobilidade e da segurança pública (ARTICULAÇÃO NACIONAL DOS COMITÊS POPULARES DA COPA, 2012).

Em síntese, o documento denuncia a enorme expectativa de remoções vinculadas às obras - estimadas em 170 mil. Denuncia também o fato de que as informações sobre obras e recursos investidos, bem como os próprios processos decisórios, estejam restritas a entidades privadas e a representantes de governos, sem a possibilidade de participação da população em geral, muito menos dos grupos diretamente afetados pelas obras, como moradores de favelas, população em situação de rua e trabalhadores ambulantes.

O Dossiê foi elaborado numa linguagem de fácil compreensão e, juntamente com um conjunto de estratégias de divulgação desse - envio às autoridades do governo federal, à Câmara dos 
Deputados, Câmaras de Vereadores nas cidades-sede, Ministérios Públicos Federal e Estaduais - e teve como função principal tornar-se uma peça de denúncia que pudesse sensibilizar mais sujeitos sociais a reforçar o campo da luta pelos direitos humanos. Não se trata de um documento com a pretensão de registrar números precisos ou realizar análises profundas sobre os vários temas, mas de uma peça de mobilização e de registro de uma pauta de reivindicações consensuadas entre as entidades que compõem os vários Comitês.

Pode-se notar que essas estratégias se formaram em paralelo a outras formas de incidência na política urbana, como a campanha pela instituição do GT Direito Humano à Moradia Adequada, junto ao Conselho de Defesa dos Direitos da Pessoa Humana (CDDPH), órgão vinculado à Secretaria de Direitos Humanos da Presidência da República7; Campanha pela Função Social da Propriedade Urbana; e ações de apoio a mudanças no Código de Processo Civil sobre conflitos fundiários ${ }^{8}$.

Basicamente, pode-se elencar como pauta de reivindicação9:

1. Transparência e acesso à informação;

Os planos, projetos, cronogramas, convênios e ações promovidos no âmbito da Copa do Mundo e Olimpíadas devem ser de domínio público, inclusive e, principalmente, das comunidades diretamente afetadas.

2. Publicização das informações sobre recursos destinados às obras infraestruturais da Copa do Mundo;

7 O GT teve sua primeira reunião em junho do presente ano, com um escopo muito mais amplo do que as violações de direitos ocorridas a partir dos megaeventos esportivos; sua efetividade, enquanto espaço para incidência sobre as iniciativas ligadas à preservação dos direitos humanos, ainda deverá ser avaliada.

${ }^{8}$ Coordenada pelo Fórum Nacional da Reforma Urbana, a campanha tem como lema: A cidade não é um negócio, a cidade é de todos nós. O Fórum Nacional pela Reforma Urbana (FNRU) elaborou uma proposta de emendas para o PL 8046/2010, que dispõe sobre o novo Código de Processo Civil; as emendas referem-se a propostas de mecanismos de mediação de conflitos urbanos e rurais, obrigando o judiciário a instituir audiência prévia de conciliação e a verificar o cumprimento da função social da propriedade, ambos antes de deferir pela reintegração de posse. 9 Síntese baseada na Carta Aberta, de março de 2011, elaborada pela ANCOP, pode ser encontrada: Carta da Articulação Nacional dos Comitês Populares. Anexo 1 do Dossiê Megaeventos e Violação de Direitos Humanos no Brasil (ARTICULAÇÃO NACIONAL DOS COMITÊS PÓPULARES DA COPA, 2012). 
Direitos trabalhistas respeitados nas obras de construção das infraestruturas e equipamentos, bem como em todos os serviços relacionados aos jogos sem perseguição e criminalização dos ambulantes e trabalhadores informais.

3. Despejo zero na realização dos eventos da Copa do Mundo e Olimpíadas;

4. Realização de Consultas Públicas, com garantia de efetiva participação popular, particularmente das comunidades diretamente afetadas;

5. As ações de segurança e intervenção urbanística devem respeitar e efetivar os direitos humanos, com a intenção de melhorar a realidade urbana e as condições de vida de populações vulneráveis, como moradores de assentamentos informais e cortiços, crianças e adolescentes, trabalhadores informais, comunidades indígenas e afrodescendentes, população em situação de rua, artistas populares, entre outros;

6. Legado socioambiental e de ampliação de direitos;

O saldo final dos investimentos e políticas de incentivos praticados para viabilizar os megaeventos deve ser de um legado socioambiental positivo para toda a sociedade, de modo que sejam ampliados os direitos humanos, sociais, econômicos, culturais e ambientais e fortalecidas as redes e políticas voltadas para economia solidária e promoção da inclusão e equidade socioespacial. Para tanto, deve ser construído um plano de compromisso em diálogo com as organizações não governamentais, movimentos sociais e comunidades afetadas.

7. Repúdio à cidade de exceção;

A legalidade e direitos já inscritos na Constituição Federal e legislação brasileira não podem ser suspensos em função e para a realização dos jogos.

Enfim, das reflexões realizadas, podem-se encaminhar as conclusões do trabalho. O diálogo com os diversos autores pesquisados evidenciou que o espaço urbano é espaço político e econômico de disputa, tanto para os objetivos de rentabilidade e competitividade do mercado, quanto para a construção de estratégias de enfrentamento as diferentes formas de subalternização e opressão da classe trabalhadora. O padrão de urbanização que se consolidou 
no Brasil expandiu-se por meio da prevalência de um urbanismo de mercado que produz a marginalização de segmentos sociais e o exílio da classe trabalhadora para regiões periféricas desprovidas de serviços. Por outro lado, exercícios de integração meramente formais e institucionais alimentam processos de desvalorização política, dificultando conquistas e consolidação dos direitos.

Em suma, respondendo à pergunta inicial, afirma-se que é possível construir formas de resistência, como essa exemplificada nos Comitês Populares, e reforçar o compromisso profissional por trabaIho, direitos e liberdade e, na mesma medida, realizar o exercício profissional direcionado para os interesses dos trabalhadores. No contexto da urbanização brasileira, isso significa romper com heranças históricas que mantiveram a classe trabalhadora alijada dos processos decisórios, e posicionar-se na luta pelo direito à cidade.

São reflexões que, espera-se, possam fortalecer esperanças nas possibilidades de transformação da realidade social ao lado dos movimentos sociais, e que demandam, mais do que nunca, compromisso ético político dos assistentes sociais.

\section{REFERÊNCIAS}

AMARAL, Angela. O Serviço Social e a construção da unidade nas lutas contra as reformas neoliberais. In: ENCONTRO NACIONAL CFESS-CRESS, 36., 2007, Natal (RN). Conferências e Deliberações do $36^{\circ}$. Encontro Nacional CFESS-CRESS. Natal, 2007.

ANTUNES, Ricardo. Os sentidos do trabalho: ensaio sobre a afirmação e a negação do trabalho. São Paulo: Boitempo Editorial, 1999.

ANTUNES, Ricardo. Trabalho e precarização numa ordem neoliberal in La Ciudadania Negada. In: POLÍTICAS de Exclusión en la Educación y el Trabajo. CLACSO, 2000. Cap. 2. Disponível em: <http://bibliotecavirtual.clacso.org.ar/clacso/gt/20101010021549/3antunes.pdf>.

ARTICULAÇÃONACIONALDOSCOMITÊSPOPULARESDACOPA(Brasil). Dossiê Megaeventos e Violação de Direitos Humanos no Brasil. Jun. 2012. Disponível em: <http://www.portalpopulardacopa.org. br/index.php?option=com_k2\&view=item\&id=198:dossi\%C3\%AA-nacional-de-viola\%C3\%A7\%C3\%B5es-de-direitos-humanos> e também em: <http://pfdc.pgr.mpf.gov.br/temas-de-atuacao/megaeventos/dossie_violacoes $>$. 
BEHRING, Elaine. Expressões políticas da crise e as novas configurações do Estado e da sociedade civil. In: SERVIÇO Social: direitos sociais e competências profissionais. Brasília: CFESS/ABEPSS, 2009. BRASIL. Constituição Federal 1988. Constituição da República Federativa do Brasil. Brasília: Senado Federal, 1988.

BRASIL. Lei $n^{\circ} 10.257$, de 10 de julho de 2001. Regulamenta os arts. 182 e 183 da Constituição Federal, estabelece diretrizes gerais da política urbana e dá outras providências. Disponível em: < http:// www.planalto.gov.br/ccivil_03/leis/leis_2001/110257.htm>.

CASTEL, Robert. La montée des incertitudes: travail, protections, statut de l' índividu. Paris: Éditions du Seuil, 2009.

CONSELHO FEDERAL DE SERVIÇO SOCIAL (Brasil). Código de Ética do/a Assistente Social comentado. Org. Maria Lucia Barroco e Sylvia Helena Terra. 1.ed., 1. reimpr. São Paulo: Cortez; Brasília: CFESS, 2012.

CORDEIRO, Berenice da Silva; BRITTO, Ana Lucia; PEREIRA, Tatiana Dahmer. A política nacional de saneamento: notas sobre avanços e impasses nos governos Lula (2003- 2010). In: ENCONTRO NACIONAL DA ANPUR, 14., 2011, Rio de Janeiro. Anais... Rio de Janeiro: ANPUR, 2011.

ENGELS, F. A questão da habitação. Trad. Dainis Karepovs. São Paulo: Ed. Acadêmica, 1987.

HARVEY, David. A produção capitalista do espaço. São Paulo: Anablume, 2005.

HARVEY, David. O novo imperialismo. 3. ed. São Paulo: Edições Loyola, 2009.

HOBSBAWN, Eric. A era dos extremos: o breve século XX - 19141991. 1. reimpr. Trad. Marcos Santanela, Revisão Técnica Maria Célia Paoli. São Paulo: Cia. das Letras, 1995.

HABITAT INTERNATIONAL COALITION (HIC); FÓRUM NACIONAL DA REFORMA URBANA (FNRU); ALIANZA INTERNACIONAL DE LOS HABITANTES (AIH). El derecho a La ciudad. Rio de Janeiro, abr. 2012. Documento Rio+20.

IAMAMOTO, Marilda Villela. Serviço Social em tempo de capital fetiche: capital financeiro, trabalho e questão social. São Paulo: Cortez, 2007. 
IAMAMOTO, Marilda Vilela. O Serviço social na cena contemporânea. In: SERVIÇO Social: direitos sociais e competências profissionais. Brasília: CFESS/ABEPSS, 2009.

KOWARICK, Lucio. Escritos urbanos. São Paulo: Ed. 34, 2000.

KOWARICK, Lucio. Viver em risco: sobre a vulnerabilidade socioeconômica e civil. Fotografias de Antonio Saggese. São Paulo: Ed. 34, 2009. LEFEBVRE, Henry. 0 direito à cidade. Trad. de Rubens Eduardo Frias. São Paulo: Ed. Moraes, 1991.

MARANHÃO, Cézar Henrique. Desenvolvimento social como liberdade de mercado: Amarthya Sem e a renovação das promessas liberais. In: MOTA, Ana Elizabete (Org.). As ideologias da contrarreforma e o serviço social. Recife: Ed.Universitária da UFPE, 2010.

MARICATO, Ermínia. As ideias fora do lugar e o lugar fora das ideias - planejamento urbano no Brasil. In: ARANTES, Otília; VAINER, CarIos; MARICATO, Ermínia. A cidade do pensamento único: desmanchando consensos. 6. ed. Petrópolis, RJ: Vozes, 2011.

MARICATO, Ermínia. O impasse da política urbana no Brasil. Petrópolis, RJ: Vozes, 2011.

MARICATO, E.; SANTOS Jr., Orlando. Dossie: Conferencias nacionais - uma política urbana participativa. Teoria e Debate, n. 66, abr./maio 2006. Disponível em: <http://www3.fpabramo.org.br/o-que-fazemos/editora/teoria-e-debate/edicoes-anteriores/dossie-conferencias-nacionais-uma-politica>.

MARICATO, Ermínia. Brasil, cidades: alternativas para a crise urbana. Petrópolis, RJ: Vozes, 2001.

MOTA, Ana Elizabete (Org.). As ideologias da contrarreforma e o Serviço Social. Recife: Ed.Universitária da UFPE, 2010.

MOTA, Ana Elisabete. A ofensiva de desregulamentação no capitalismo contemporâneo: tendências destrutivas das reformas neoliberais no Serviço Social. In: ENCONTRO NACIONAL CFESS-CRESS, 36., 2007, Natal (RN). Conferências e Deliberações do $36^{\circ}$. Encontro Nacional CFESS-CRESS. Natal, 2007.

MOTA, Ana Elizabete; AMARAL, Angela Santana; PERUZZO, Juliane 
Feix. O novo desenvolvimentismo e as políticas sociais na América Latina. In: MOTA, Ana Elizabete (Org.) As ideologias da contrarreforma e o Serviço Social. Recife: Ed.Universitária da UFPE, 2010.

NETTO, José Paulo. Ditadura e Serviço social: uma análise do Serviço Social no Brasil pós 64. São Paulo: Cortez, 1991.

NETTO, José Paulo; BRAZ, Marcelo. Economia Política: uma introdução crítica. São Paulo: Cortez, 2006.

OLIVEIRA, Francisco de. Privatização do público, destituição da fala e anulação da política: o totalitarismo neoliberal. In: PAOLI, M.C. P. M; OLIVEIRA, F. Os sentidos da democracia: políticas do dissenso e a hegemonia global. 2.ed. Petrópolis, RJ: Vozes, Brasília: NEDIC, 1999.

PAULANI, Leda Maria. Brasil Delivery: servidão financeira e estado de emergência econômico. São Paulo: Boitempo, 2008.

RAICHELIS, Raquel. Esfera Pública e Conselhos de Assistência Social: caminhos da construção democrática. São Paulo: Cortez, 1998.

RAICHELIS, Raquel. O Assistente Social como trabalhador assalariado: desafios frente à violação de seus direitos. Revista Serviço Social e Sociedade, São Paulo, n. 107, 2011.

ROLNIK, Raquel. A lógica da desordem. Le Monde Diplomatique Brasil, São Paulo, ano 2, n. 13, ago. 2008. Disponível em: <http://www. diplomatique.org.br/edicoes_anteriores_det.php?edicao=14>.

SANTOS, Silvana Mara de Morais; BOSCHETTI, Ivanete. 30 anos do Congresso da Virada CFESS Manifesta. Brasília: CFESS, 2011. Divulgado em 16 nov. 2009.

VIEIRA. Evaldo. Os direitos e a Política Social. São Paulo: Cortez, 2004. VIEIRA, Evaldo. Estado e Miséria Social no Brasil: de Getúlio a Geisel. São Paulo: Cortez, 1983.

WOOD, Ellen Meiksins. A origem do capitalismo. Trad. Vera Ribeiro, apresentação Emir Sader. Rio de Janeiro: Jorge Zahar, 2001. 